Accepted by Studies in Higher Education

September 2010

\title{
Time is not enough: promoting strategic engagement with writing for publication
}

\author{
Authors: Iain MacLeod, Laura Steckley and Rowena Murray \\ Affiliation: University of Strathclyde
}

\author{
Contact information: \\ Iain MacLeod \\ Glasgow School of Social Work \\ Sir Henry Wood Building \\ University of Strathclyde \\ 76 Southbrae Drive \\ Glasgow G13 1PP \\ Scotland, UK
}

Research, scholarship and publication are central to the work of higher education. However, even academics with the necessary research and writing skills can struggle to publish as often as they would like. Research suggests that a writing retreat is one solution; there is a process going on there that addresses the problem, but how it does so has not been fully explained. We used a novel approach, containment theory, to explain why the functions of a structured retreat work. We argue that a retreat does more than simply provide time to write; it is a model for academics to meet the demands of research assessment. Finally, we conceptualise this as strategic engagement - a model for producing regular writing for publication while continuing to meet other professional demands. 


\section{Introduction}

There has been much discussion about academic output, its impact and the nature of academic work. The condition of higher education has been characterised as 'supercomplexity' (Barnett, 1999) and strategic dissonance (Winter, Taylor, and Sarros, 2000). The demands on academics are explicit, but they can also be contradictory (Carnell et al. 2008). Where there is increased 'performativity' (Acker and Armenti, 2004; Ball, 2003; Hey, 2001) there can be pressure and anxiety, as academics attempt to manage demands and meet targets for different strands of their work and different audiences for their writing. What has been missing from this debate is an explanation of how academics might manage this complexity.

For some, the answer is simple, 'work harder and longer' (Acker and Armenti, 2004, p. 16), and while this may not be the safest, most sustainable or conceptually sound way for academics to manage competing demands, academics will have to find ways to manage these demands. Some may baulk at this prospect and decide not to write, in order to protect their personal time or focus on their own interests. Others may perceive publication as 'constricted' (Badley, 2009, p 146), and perhaps constructed by the views and interests of a select, privileged or élite few. These issues currently merit consideration because they are not exclusive to higher education; they are also relevant to an increasing number of educational settings (Solbrekke, 2008; Turner, Hughes and Brown, 2009), where the importance of research, scholarship and publication is growing.

How academics and others conceptualise this 'performative' context, and how they learn to negotiate and balance different demands has not yet been established (Clegg, 2008). However, apart from being interviewed for studies of academic work, where can academics articulate their positions in this debate? Where can they constructively address factors affecting their research output? Where can they express and process their 
aspirations and concerns? Formal processes, like career review and appraisal, monitor outputs and define workloads, but these are not always reflective, learning opportunities. Academics can talk to their colleagues, but this is not always productive or safe, nor are there regular, routine, dedicated discussions of these issues. Moreover, if everyone is working 'harder and longer' (Acker and Armenti, 2004, p. 16) who has time to talk? One forum where we see academics discussing these issues and establishing positions in this debate is a writing retreat. While it is intended to stimulate writing and generate publications, a retreat also provides time and space for reflection on writing more broadly.

Originally, the idea of a writing retreat was based on the principle that removing academics from normal working environments would circumvent cultural and personal forces that inhibit writing (Grant and Knowles, 2000; Grant, 2006). Retreats were found to improve well-being and increase motivation to write (Moore, 2003). Structured retreats developed academics' conceptualisations of writing-in-progress and increased outputs (Murray and Newton, 2009).

We do not assume that it is desirable or possible to increase academic publication indefinitely; our concern and inquiry are focused on those academics who want to write but find that they cannot. In the current competitive publishing culture it would be unethical not to address this problem, given the serious consequences for academic careers of failing to publish. Realistically, there may never be enough journal space for every academic to publish four articles in every assessment cycle (as was expected by the UK's Research Assessment Exercise) but surely we would not attempt to limit outputs by withdrawing support? There will always be selectivity, but it should not be assumed that academics are all equally prepared for the selection process. A key function of writing retreat is to provide a forum for discussing these issues.

While previous studies defined the challenge of writing for publication and proposed strategies for meeting that challenge, we felt there was a need for a theorized understanding of underlying issues within the context of research assessment, which, in 
one form or another, is what has come to set the international standard for academic performance in research. We chose containment as the theoretical framework for our study because it explained how the structure and functions of the retreat work.

The following analysis brings to light elements of writing for publication in the context of performativity and suggests that a structured retreat - which is structured in the sense that it involves a fixed programme of writing sessions, with participants all writing in the same room throughout the retreat - can help academics manage its complexity. Finally, we offer the concept of strategic engagement as a model for producing regular writing for publication while continuing to meet other professional demands.

\section{Applying containment theory to the performance of writing for publication}

We recognise that the theoretical framework advanced here is a novel approach within current discourses on understanding academic performance. While there have been other discussions of how academics manage multiple roles, this is the first time that containment has been used to theorise how they might do this. We start by defining the key components of containment theory and then explain its application to higher education.

\section{Defining primary task and anti-task}

In containment theory, the primary task of an organisation is defined as the activity that the organisation must perform in order to ensure its continued existence (Menzies-Lyth, 1988). Where the primary task of the organisation is clear, members of the organisation are more likely to derive satisfaction from the performance of that task. In contrast, poor definition of the primary task results in confusion within the organisation and increased interpersonal and inter-group conflict. Confusion in the organisation's definition of primary task increases the probability that unconscious social defences will emerge that 
defend individuals within the organisation against anxiety. Anti-task is any practice that is unconsciously used as a defence against task-related anxiety and prevents or inhibits the achievement of the primary task. The ability to recognise anti-task tendencies is predicated on clarity about the nature of the primary task. Thus, the key question to be asked at any given time is, 'Is what we are doing the primary task?' If the answer is no, then it is likely that anti-task behaviour has emerged.

\section{The impact of multiple tasks}

In higher education, there is not one primary task but multiple and competing tasks, and several tasks may be ascribed primacy at any given time. Menzies-Lyth (1988) suggests that where multiple tasks compete for primacy there is a need for the organisation to manage this process. Organisational effectiveness is reduced as efficient performance of one task is diminished by the legitimate demands of competing tasks.

In the higher education setting, it can no longer be convincingly argued that the primary task of a university is to educate. There can be no assumptions of homogeneity within the system. Clegg (2008) and Barnett (1999) have explored the fragmentation of teaching and research activity and the impact this has on academic performance. The construction of a tripartite - e.g. teaching, research and economic contribution functions structure of the higher education sector has also been explored (Ainley, 2003; Jones and Thomas, 2005) in relation both to discourses on widening participation and to the impact and influence of neo-liberal projects advanced by New Labour in the UK (Archer, 2007).

The theme that emerges from these articles is one of complexity, fluidity and multiple purposes and subject positions within the higher education sector. It is not suggested that the different organisational orientations are mutually exclusive, but rather that an understanding of the interaction of these task functions is necessary in order to understand the way in which academics will interpret and perform their role. A lack of 
clarity in defining which functions have primacy at a specific time is likely to result in task confusion and a decrease in satisfaction and productivity.

In taking up this theory, it is not our intention to argue for an end to synergies between different academic roles, but to analyse the problem that multiple purposes presents to individuals and explore how that problem might be managed. The concept of primary task does not mean focusing on writing for publication and neglecting other roles; instead, it means developing a disposition and strategy for making writing the primary task at specific times. At other times, other tasks will have primacy.

\section{Writing-related anxiety}

One of the competing primary tasks of the academic role is writing for publication, or more specifically writing for research assessment purposes. That academics can experience writing-related anxiety is well established and is most commonly referred to as writer's block, but it can take less acute, but no less serious, forms, such as failure to meet personal writing goals. Academics are not immune to such anxieties, though research into their experiences of writing is limited (Moore, 2003). As early as 1987, Boice addressed the discomfort that academics - even productive and successful academics - experienced in relation to their scholarly writing. He identified cognitions, or self-talk, that generate anxiety and other discomforts. Grant and Knowles (2000) describe women's fear of being exposed as frauds and their feelings of perfectionism and shame towards their writing. They argue that while women may face particular writingrelated struggles, many academics - men and women - fear having their inadequacies exposed in their published writing.

Practical difficulties are also experienced by academic writers, the most common of which are described as competing demands for their time (Boice, 1987; Grant and Knowles, 2000; Moore, 2003). Inability to make adequate time and space for writing can

elicit feelings of guilt and dread towards uncompleted writing projects. These anxieties, 
stoked by external forces, can result in feelings of pressure, stress and panic (Moore, 2003). Thus, it is not simply the personal anxieties academics bring to their writing that impact on their productivity; environmental aspects, in which organisational dynamics play a significant part, require deeper consideration.

Finally, anxiety can be created by competing forms of publication. Even experienced writers have difficulty balancing the demands of, for example, writing for journals that have an impact factor and writing in order to have an impact in other ways, such as on practice (Carnell et al., 2008).

\section{Barriers to effective task performance}

Where there is scope for multiple interpretations of primary task it is likely that there will be individual and idiosyncratic interpretations of the task. It is these individual definitions that have the potential to produce anti-task practices. Where there are no mechanisms within the organisation for a reflexive exploration of task complexity, theory predicts that the anxiety that task confusion elicits will be evidenced in the construction of social defences that are observable in the day-to-day practices of staff. Developing an organisational awareness and understanding of these processes illuminates the difficulties academics face in relation to writing for publication in a performative context. In healthy organisational cultures there are likely to be structures and processes that actively support the management of anxiety associated with task performance. These processes have been defined as containment.

\section{Containment}

The notion of containment (Bion, 1962) focuses on the processes that enable people to manage (contain) previously unmanageable (uncontainable) thoughts, feelings and experiences. Theories of containment have been applied to other settings, including 
social work (Toasland, 2007), social work education (Ruch, 2005, 2007; Ward, 2008) and business (Kahn, 2001). The processes of containment initially occur between parent and infant, enabling the development of thinking to manage raw experience and emotion. Thus, a person who is in a state of containment, usually from a combination of internal and supportive external processes, is able to think clearly about and manage experiences and emotions.

For a variety of reasons, people often have experiences and emotions that they are not able to contain. These can be experienced in obvious conscious ways in periods of crisis, or as the more subtle, disruptive effects of anxiety on clear thinking.

Ruch (2005) offers a model of 'holistic containment' as a framework for understanding the multifaceted dimensions of containment and suggests how they can be promoted at an organisational level. The model has three facets: emotional containment, which focuses on how unthinkable or unmanageable feelings can be made thinkable and manageable; organisational containment, which focuses on how policies, procedures and organisational practices contribute to organisational, professional and managerial clarity; and epistemological containment, which focuses on forums that enable members of the organisation to think about, discuss and make sense of contentious, uncertain and/or complex issues related to their work. The combination of Ruch's (2005) three facets in holistic containment offers a systemic approach to understanding the interdependence of the individual and the collective context in providing work environments that are containing. It serves as a framework for our analysis of academics' writing for publication.

To sum up, the position advanced here is that understanding conscious and unconscious processes that exist within all institutions is a useful means of facilitating change. The operation of these processes has been defined by Obholzer (1986):

... inherent in every task - and institutions are set up to perform specific tasks there is the anxiety, pain and confusion arising from attempting to perform the 
task; and ... institutions defend themselves against this anxiety by structuring themselves, their working practices and ultimately their staff relationships in such a way as to unconsciously defend themselves against the anxiety inherent in the task (1986, p. 202).

The potential for a writing retreat to contain anxiety related to the performance of writing for publication is explained in this article.

\section{Methodology}

Aims

We set out to establish the extent to which attending a writing retreat enabled participants to overcome barriers to writing on return to their work settings. Funding for the study was provided by the British Council. Ethical approval was granted by the University of Strathclyde.

Our study had three objectives:

1. To identify barriers to writing for publication in academic contexts that had persisted since the writing retreat;

2. To identify strategies respondents used to overcome these barriers;

3. To identify changes in writing for publication practices, particularly those that led academics to achieve their writing goals. 


\section{Respondents}

Forty participants in one or more of six retreats between September 2005 and March 2006 were contacted by email and invited to take part in the research. All were given an information sheet and consent form and asked to suggest a date and time for interview, if they agreed to take part in the study. Three did not reply, two declined, three had left the university and five said they did not have time to be interviewed.

\section{Data collection}

Twenty-seven respondents (15 females, 12 males) participated in thirty-minute semistructured interviews. Interviews were transcribed verbatim. Respondents ranged from experienced (3) to novice (3), with the majority describing themselves as 'less experienced'. Eighteen had attended more than one retreat.

\section{Data analysis}

Based on the theoretical assumptions outlined above, we developed a coding system for analysing the transcripts. The codes we used were Primary Task, Anti-Task, Anxiety, Emotional Containment, Organisational Containment, Epistemological Containment and Holistic Containment. Analysis and coding drew on Ritchie and Spencer's (1994) model of framework analysis, which assumes that a priori codes may be extant. Data were coded using NVIVO 8.0, which allows comparison between and within transcripts.

Narratives for each of the codes were defined as follows:

- primary task refers to any instance of a task or duty associated with academic role where this task is given primacy over other tasks within that role; 
- anti-task refers to any activity, conscious or unconscious, that prevents the accomplishment of the primary task and defends against task-related anxiety;

- anxiety refers to any description of fear, unease or disquiet that has an explicit association with the performance of activities associated with academic role.

- emotional Containment refers to qualities or experiences of the retreat that appear to enable respondents to think about or manage unthinkable or unmanageable feelings;

- organisational containment refers to practices within and related to the retreat that appear to contribute to increasing organisational, professional and managerial clarity;

- epistemological containment refers to the experiences of the retreat that appear to support respondents in making sense of their writing for publication projects, their approach to writing for publication and/or seeing writing for publication as central to their academic role and function;

- holistic containment refers to experiences of the retreat that appear to integrate the three dimensions of containment (emotional, organisational and epistemological).

These are not discrete or independent constructs; they are inter-related, interdependent, and overlapping.

\section{Findings}

\section{Emotional containment}


Over two thirds of respondents spoke of anxiety-provoking difficulties related to writing for publication: anxiety provoked by the act of writing and anxiety provoked by competing primary tasks. Both were reflected in the struggle to manage competing academic roles, were interrelated and had a compounding effect on each other.

Respondents described feeling worried, apprehensive, embarrassed, unconfident and even pained by the process of writing for publication and/or the inability to achieve their writing goals. One described experiencing rejection of an article as 'traumatic', and another described unfinished writing as 'one of those things that woke me up at three in the morning just worrying about it'.

Given the discomfort that so many respondents related to writing for publication, it is arguable that at least some may unconsciously defend against this by engaging in antitask behaviour. A few respondents appeared to have an emerging awareness of their antitask tendencies, describing habits of procrastination or using distractions. The following quotation illustrates how participating in the retreat enabled one respondent to see and address anti-task tendencies:

I was aware at the writer's retreat of the frustration, of feeling that you were attempting to achieve something that was very challenging, and I suppose the intensity of the writer's retreat meant that on a consistent basis you were having to face that frustration over the course of the weekend, whereas in daily practice, instead of facing that frustration, I think I avoid it sometimes.

One third of the total number of respondents did not explicitly identify anxiety related to writing for publication; however they did say that they found it difficult to prioritise writing.

A minority of respondents contradicted themselves during the interview in a manner that seemed to reflect ambivalence. For example, one experienced writer described enjoying writing and claimed to have no problems with writing for publication. However, later in the interview he/she spoke about perfectionism and said it interfered with 'getting on with 
[writing]'. This contradiction can be viewed as a defence against the seemingly overwhelming task of producing the standard of writing required. It might be an indication that even experienced writers contend with anxiety and anti-task behaviours.

Almost all respondents said they felt supported by the physical, social and/or psychological aspects of the writing retreat. All spoke positively about the venue, with most identifying it as important. The food, immediate surroundings, scenic location, absence of distractions (i.e. television, telephone, internet and email) and physical distance from work and home were identified as conducive to thinking and writing:

But it's the fact that, you know, it's good surroundings. The food's good. I believe that if you cater to people's basic needs then, you know, their higher needs can be met also ... It's warm. It's an attractive setting ... as you travel up that road out of [place name deleted], out of the city, and see the mountains stretch out before you, there's something really quite liberating about that.

In providing these experiences of support, the retreat can be seen as emotionally containing. Several respondents described the momentum and motivation they gained from the retreat, with one also speaking of a similar benefit from the prospect of upcoming retreats. Interviewees also used terms like nourishing, invigorating and being well looked after to describe their experiences of the retreat.

The importance of the group was also mentioned by almost all respondents: it enabled many to manage difficult feelings related to the process of writing. Respondents spoke of the supportive atmosphere and the benefit of the social dimension. There were multiple references to collegiality, humour, encouragement and the incentive to keep going when others were doing the same task and facing the same challenge:

Well, you don't feel alone in your misery of writing, especially at the start. So I think it is very useful to know that everyone is in the same boat ... everyone has the same problems with writing, i.e. structuring or disciplining or just getting 
through putting words on paper, so that was very useful. I think because you are in a group you actually work harder.

One respondent described writing as a lonely activity and found that the company of other writers enabled her to avoid getting stuck; another spoke of how the retreat ensures that 'you're never isolated'. Most respondents described talking through issues related to their projects or to writing for publication more generally. The identified benefits of this were twofold: firstly, increased confidence from seeing more experienced writers struggling - like them - but also modelling working through those struggles; and, secondly, working through their thoughts and difficulties with other writers in a way that reduced anxiety.

A striking theme was the increase in confidence described by respondents. This was stated explicitly and repeatedly. They spoke of writing becoming less daunting, and of how the mystery surrounding writing for publication was diminished. They spoke of the growing feeling that they were capable of writing, and a few of a growing identity as a writer. This confidence was connected to a sense of achievement related to their writing, conveying the psychological satisfaction they took from task completion. One respondent spoke of the retreat easing a lot of his/her angst about levels of productivity in writing for publication. A couple of respondents described having confidence to 'say no' to demands in their work settings, so as to prioritise their writing for publication. Thus, many respondents not only began to think more clearly about the task of writing and their related habits, but were also beginning to change them.

Having explored the impact of anxiety on task performance related to writing for publication and the emotionally containing elements of the structured writing retreat, we now examine the findings in relation to the organisational factors of the retreat that provide containment. 


\section{Organisational containment}

In the majority of respondent transcripts there was a high degree of consistency in the themes that emerged in relation to organisational containment. Those that emerged most strongly were the role of the facilitator, the retreat's structure and institutional support.

While the interviewer used the term 'facilitator' to refer to the person who organised and ran the retreat, respondents' discussion of this role reflected more than simply facilitation:

... what the facilitator does is keep you on track, keep you focussed, and sometimes that appears quite forcing, in that saying it is time for a break, it's time for a stretch, it's time for ... we don't always see in ourselves the need to have a break.

The facilitator role was described by another respondent as 'cracking the whip'. The impact of the facilitator was also included by another respondent:

... had there not been a facilitator there, or even a weaker facilitator, we would have done nothing. We would have distracted each other. We would not have been focussed on writing.

This suggests that facilitator role was central to holding and maintaining boundaries and clarifying the primary task of the retreat. Respondents spoke of the struggle to protect spaces for writing for publication, given the competing and conflicting tasks that they faced in their workplaces. Many respondents reported that writing was an activity that occurred not in the workplace but in their homes. While working at home may have become the norm for academics and reflects a degree of flexibility of working, we now know that this arrangement will not necessarily provide the organisational containment that may be needed to support writing for publication. Respondents who attended retreat reported that they now used the process of structured writer's retreat when they were working at home. It appears that the benefits of structure writer's retreat and the 
organisational containment provided by the facilitator had been internalised and this in turn promoted more effective engagement with writing at home.

While three respondents expressed reservations about the rigidity of the retreat structure, the majority found it beneficial to the writing process. The perceived benefits are captured in the following quote:

Interviewer: Did you like the structure?

Respondent: I did.... being new to [writing], it is quite good having that discipline. I have tried doing it myself, and I can do it for a day. I have now used that structure myself at home.

A particular element of the structure was highlighted as useful by respondents; each writing session begins with participants setting, sharing and clarifying goals for that session. Respondents spoke of how this practice enhanced their focus and productivity and reduced their sense of being overwhelmed by writing. There was also evidence that it raised their awareness of what could be accomplished in shorter blocks of time in their writing outside of the retreat.

The benefits of the group described above are fundamentally located in the way that the retreat is structured; this structure provides greater professional clarity, as the group process provides an opportunity for the writing task to be made visible and public. It may be that this aspect provides organisational containment, while also embedding other forms of containment.

In concluding this section we must mention the importance respondents placed on support for the retreat by their departments and/or faculty. They saw a relationship between financial support for the retreat and the value their organisation attached to the activity of writing for publication. By contrast, the absence of financial support was seen 
by one respondent (who was not funded by his/her department or university) as an indication that their writing for publication was not a valued activity, and therefore it was more likely to drop down their list of competing tasks.

\section{Epistemological containment}

The findings related to epistemological containment revealed three themes: firstly, the relationship of writing and publication to the respondents' understanding of their academic roles and purposes; secondly, respondents' perception that the teaching role was seen as supporting 'real' academics in the research role - rather than as a valued component of the academic role; and thirdly respondents' reported increase in confidence and writing outputs through participation in the retreat. The emergence of these themes and the conscious consideration of them by respondents show how participation in and engagement with the process of a structured writing retreat may promote epistemological containment; that is, they show how respondents started to make sense of and integrate their writing projects with other roles and purposes within the academy.

Most respondents identified themselves as novice or less experienced writers. It was common amongst these respondents to identify writing for publication as a practice that was 'other' and an underdeveloped component of the academic role. A typical example is found in the following comments from a respondent who was in the process of transferring from MPhil to $\mathrm{PhD}$ :

... you look at everybody round you, and I just had this really strong feeling that they were academics who had been writing for years, and I felt a little bit ... belittled would be too strong ... inexperienced, probably would be a better way of putting it.

This respondent also commented on the impact of participating in the retreat: 
... maybe I am becoming a little more academic, because when I went on the writing retreat it was early days. I had been a clinician, wasn't used to writing, and I suppose now I am beginning to be able to write a bit better.

It was common for respondents to report that they were beginning to construct a sense of self, role and purpose in relation to writing for publication through participation in the retreat. It would appear that the immediacy and visibility of writing as explicit primary task within structured retreat and the protected nature of the space allowed individuals to make sense of the challenges of writing. The majority of respondents described talking through issues related to their writing projects or to writing more generally. About a third of respondents spoke of the benefit of discussions and sharing of ideas:

Just articulating what you've been writing is a useful process ... it changes your thinking having verbalised it as opposed to just having written it.

The opportunity to give and receive feedback, even across disciplines, was highlighted. A few respondents described a transformation in their thinking and practices related to writing. It was evident in their answers that the processes of discussing writing and goalsetting for writing allowed them to make sense of their writing projects and practices. This reflects epistemological containment, and once it has been experienced at a retreat, it is more likely to be experienced outside the retreat setting, as the individual can draw on increased understanding of the process. The process of writing helps the individual to understand why writing is central to the academic role. In this sense, it is an integrative practice that clarifies the role and purpose of an academic.

The relationship between writing for publication and teaching as components of the academic role was captured by the following respondent:

Interviewer: You're expected to write papers, are you?

Respondent: Em, yes, to a certain extent, although the dedicated researchers who've been selected are really the ones who are charged with the task of writing 
papers for publication, which we have within the [named department]. Dedicated researchers ... my perception is it's our job to support them, support them by doing extra teaching.

The views expressed here illustrate the complexity of managing the academic role. If writing for publication is perceived (especially by early career academics) as an aspect of academic role and purpose that is 'other', then it would seem that, for some, their primary task has been implicitly redefined as supporting dedicated researchers by 'doing extra teaching'. Beyond the environment of the retreat it is likely that such respondents will experience a degree of confusion in reconciling their day-to-day activities, such as teaching, with the expectation that they will also be productive in writing for publication. Thus, in the retreat environment the experience of epistemological containment may only occur for those who are willing to shift their self-perception to include writing for publication as a legitimate role. Alternatively, those who have already made this shift may experience epistemological containment in making sense of their current writing projects.

\section{Holistic containment}

Almost half of the respondents provided evidence that they experienced the writing retreat in a holistically containing way (i.e. providing emotional, organisational and epistemological containment):

It was good just having time away when you weren't preoccupied with everything else that you were doing, and I think what was also very helpful was having that discipline of writing together around the table and then getting critical feedback from somebody else, and it was quite a nourishing and supported environment because it was a nice setting.... you didn't have to worry about getting the tea, and you used the lunches and coffee breaks to talk about issues that you were working on. It was concentration but relaxation. It was a combination of things 
really ... I valued the discipline and structure of that supported environment, but also that built-in critical feedback. There was a good mix of people, lots of energy, and I think just in terms of eating together in the evenings was good and all around one table, because I think there is a symbolic thing in that shared purpose.

This combination not only enabled much higher levels of productivity at the retreat, as stated by most respondents, but also led to changes in respondents' approaches to writing for publication after the retreat. They made practical changes: writing more frequently for shorter periods of time, prioritising time to write, protecting time to write and using targets to develop a greater sense of focus and achievement. This involved changing how they thought about writing, in terms of demystifying the process of writing for publication, experiencing it as achievable and considering it a valid use of their time (i.e. seeing it as the primary task).

Thus, it appears that for many respondents, the experience of holistic containment at the retreat enabled the development of self-containment outside the retreat. Most respondents commented on this process being gradual, with modest claims of change. This highlights the importance of conceptualising containment as dynamic. It is not something one achieves once and for all time; it is an interactional dynamic that is fluid, as it develops and reshapes over time. This finding highlights the limitations of purely technical-rational approaches to the challenges academics face related to writing.

\section{Discussion}

Our findings suggest that the difficulty of identifying primary task in writing for publication is related to a tendency towards anti-task, and that this inhibits writing. In addition, respondents identified anxieties that inhibited writing for publication. Containment theory thus allowed us to get under the surface of writing problems and 
issues. While others have identified the development needs of new writers (Aitchison, 2009; Aitchison and Lee, 2006; Aitchison, Kamler and Lee, 2010) using pedagogical frameworks, sometimes with an emphasis on discipline structures (Kamler, 2008), we theorised writing for publication as a series of strategic engagements. Structured retreat enables these engagements. This revises our understanding of the needs of academic writers: there must be mechanisms to support staff in defining and achieving the primary task, managing task-related anxiety, identifying anti-task tendencies and managing competing primary tasks. We suggest that support at departmental and faculty level is central to the success of this approach.

The benefit of the structured retreat can be explained through the function of containment and clarity of focus on the primary task of writing. Analysis of interviews shows the shift from, 'the organisation is telling me to do this' to a collective, collegiate approach through holistic containment (Ruch, 2007). While other researchers have explored responses in writer's groups and retreats (Lee and Boud, 2003), we have provided a theoretical framework for explaining how structured retreat works. In synthesising our findings and extending their application within higher education, we offer the concept of strategic engagement, a new term to capture the dynamic approach to the multiple tasks that make up academic work. While Mayrath (2008) found that the ability to disengage from competing tasks in order to engage with writing was a characteristic of highly successful academic writers (i.e. those who publish frequently in high-impact journals), strategic engagement furthers thinking about the development of the academic role and the management of competing primary tasks. It takes us beyond a teaching-research dichotomy, towards an integrated academic identity that can hold both.

We suggest that some academics may benefit from structured retreats that allow them to develop strategic engagement. This could be particularly relevant at a time when academics must learn to integrate fragmenting roles (Clegg, 2008) and navigate the increasingly contested terrain of higher education (Winter, Taylor and Sarros, 2000). This study shows that the structured retreat is one way of developing the integrated academic roles appropriate to this complex environment. It adds to our hitherto limited 
understanding of how academics construct a sense of role in this environment (Gardner, 2008); it represents the performance of academic role not as a set of strands ( $\AA$ kerlind, 2005) but as a series of strategic engagements.

\section{Conclusion}

Others have made the case for writing retreat, but without a theoretical understanding it is difficult to translate these findings into day-to-day academic writing practice. This article adds to our understanding of the mechanisms involved in its effect. The key to its impact is holistic containment. Without containment, writing cannot be prioritised, and academics will not write as much as they want to. This article offers a theoretical framework to build a better understanding of how structured retreat functions to support change in writing experiences and behaviours in the context of current academic working conditions. While others have established that retreat participants are satisfied and productive at writing retreat, we have established why it is satisfying and how it is productive.

Moreover, we have shown that the benefits of writing retreat are not just the result of increasing time for writing; nor is it just about creating an exclusive focus on the act of writing. These benefits were indeed experienced by respondents, but using containment theory allowed us to reveal the functions that make the retreat work: containing writingrelated anxiety, helping writers to negotiate multiple tasks, positioning writing as the primary task and preventing anti-task behaviour.

We identified some of the factors that enable or prevent academics from making time and space to write. We developed the concept of strategic engagement to explain the process of integrating writing for publication in academic work. This new concept is a model for managing the competing primary tasks of academic work for those who want to increase and/or improve their writing for publication. It is through engagement with the process 
of writing - as at structured retreat - that strategic engagement develops; if there is no engagement with the process, there may little or no writing or publication.

The writing retreat has benefits, but it is not a panacea; organisations must be clear about workloads, roles and tasks. While there is evidence that structured retreats have impact, they cannot overcome organisational practices that contribute to lack of clarity about primary tasks and otherwise contribute to anxiety. They also cannot provide containment for the 'supercomplexity' (Barnett, 1999) and strategic dissonance (Winter, Taylor and Sarros, 2000) that academics face in developing and maintaining an academic identity. If people have unrealistic workloads, a retreat will make little difference to their performance in writing for publication. Moreover, if academics do not have a site for negotiating 'conflicts of interests in daily situations at work' (Solbrekke, 2008, p. 496), they may prioritise other tasks and not write. This could be particularly damaging for new academics.

There are implications here for the academy: in a performative culture, where academics have responsibility for managing competing primary tasks, containment is needed if academics are to make writing - and other tasks - manageable and meaningful to them. Containment is therefore central to productivity. It is also crucial for academics' motivation to write for research assessment.

Word Count: 7,253(including references)

\section{Acknowledgements}

We would like to thank the British Council for funding this research, Mary Newton for conducting the interviews and the referees for their insightful and supportive comments, which helped us to improve this article. 


\section{References}

Acker, A. and C. Armenti 2004. Sleepless in academia. Gender and Education 16(1): 324.

Ainley, P. 2003. Towards a seamless web or a new tertiary tripartism?: the emerging shape of post-14 education and training in England. British Journal of Educational Studies 51(4): 390-407.

Aitchison, C. 2009. Writing groups for doctoral education. Studies in Higher Education 34(8): 905-916.

Aitchison, C., B. Kamler and A. Lee, eds. 2010. Publishing pedagogies for the doctorate and beyond. London: Routledge.

Aitchison, C. and A. Lee. 2006. Research writing: problems and pedagogies. Teaching in Higher Education 11(3): 265-278.

Åkerlind, G.S. 2005. Academic growth and development - how do university academics experience it? Higher Education 50: 1-32.

Archer, L. 2007. Diversity, equality and higher education: a critical reflection on the ab/uses of equity discourse within widening participation. Teaching in Higher Education 12(5): 635-653.

Badley, G. 2009. A place from where to speak: the university and academic freedom British Journal of Educational Studies 57(2): 146-163.

Ball, S.J. 2003. The teacher's soul and the terrors of performativity. Journal of Education Policy 18(2): 215-228. 
Barnett, R. 1999. Realizing the university in an age of supercomplexity. Buckingham: Society for Research into Higher Education-Open University Press.

Bion, W.R. 1962. Learning from experience. London: Karnac.

Boice, R. 1987. A program for facilitating scholarly writing. Higher Education Research and Development 6: 9-20.

Carnell, E., J. MacDonald, B. McCallum and M. Scott. 2008. Passion and politics: academics reflect on writing for publication. London: Institute of Education.

Clegg, S. 2008. Academic identities under threat? British Educational Research Journal 34: $329-345$.

Gardner, S.K. 2008. "What's too much and what's too little?": the process of becoming an independent researcher in doctoral education. Journal of Higher Education 79: 326351.

Grant, B. 2006. Writing in the company of other women: exceeding the boundaries. Studies in Higher Education 31: 483-495.

Grant, B. and S. Knowles. 2000. Flights of imagination: academic writers be(com)ing writers. International Journal for Academic Development 5: 6-19.

Hey, V. 2001. The construction of academic time: sub/contracting academic labour in research. Journal of Education Policy 16(1): 67-84. 
Jones, R. and L. Thomas 2005. The 2003 UK government higher education white paper: a critical assessment of its implications for the access and widening participation agenda. Journal of Education Policy 20(5): 615-630.

Kahn, W.A. 2001. Holding environments at work. Journal of Applied Behavioural Science 37(3): 260-279.

Kamler, B. 2008. Rethinking doctoral publication practices: writing from beyond the thesis. Studies in Higher Education 33(3): 283-294.

Lee, A. and D. Boud. 2003. Writing groups, change and academic identity: Research development as local practice. Studies in Higher Education 28: 187-200.

Mayrath, M.C. 2008. Attributions of productive authors in educational psychology journals. Educational Psychology Review 20: 41-56.

Menzies-Lyth, I. 1988. Containing anxiety in institutions: selected essays, volume one. London: Free Association Books.

Moore, S. 2003. Writers' retreats for academics: exploring and increasing the motivation to write. Journal of Further and Higher Education 27: 333-342.

Murray, R. and M. Newton. 2009. Writing retreat as structured intervention: margin or mainstream? Higher Education Research and Development 28: 541-553.

Obholzer, A. 1986. Institutional dynamics and resistance to change. Psychoanalytic Psychotherapy 2(3): 201-206.

Ritchie, J. and L. Spencer 1994. Qualitative data analysis. In Analyzing Qualitative Data, eds. A. Bryman and G. Burgess (pp. 173-194). London: Routledge. 
Ruch, G. 2005. Reflective practice in contemporary child-care social work: the role of containment. British Journal of Social Work 37: 659-680.

Ruch, G. 2007. 'Knowing', mirroring and containing: experiences of facilitating child observation seminars on a post-qualification child care programme. Social Work Education 26(2): 169-184.

Solbrekke, T.D. 2008. Professional responsibility as legitimate compromises - from communities of education to communities of work. Studies in Higher Education 33(4): 485-500.

Toasland, J. 2007. Containing the container: an exploration of the containing role of management in a social work context. Journal of Social Work Practice 21(2): 197-202.

Turner, R., J. Hughes and T. Brown 2009. Putting the I into identity and other stories: scholarly approaches to the professional identity and development of HE [higher education] practitioners in FE [further education] colleges. Plymouth: HELP-CETL.

Ward, A. 2008. Beyond the instructional mode: creating a holding environment for learning about the use of self. Journal of Social Work Practice 22(1): 67-83.

Winter, R., T. Taylor and J. Sarros 2000. Trouble at mill: quality of academic worklife issues within a comprehensive Australian university. Studies in Higher Education 25(3): 279-294. 